\title{
Corrosion resistance of BIS 2062-grade steel coated with nano-metal-oxide mixtures of iron, cerium, and titanium in the marine environment
}

\author{
P. Muhamed Ashraf ${ }^{1}\left[\right.$ D $\cdot$ R. Anuradha ${ }^{1}$
}

Received: 5 August 2017 / Accepted: 27 November 2017 / Published online: 3 February 2018

(c) Springer-Verlag GmbH Germany, part of Springer Nature 2018

\begin{abstract}
BIS 2062-grade carbon steel is extensively used for fishing boat construction. The steel is highly susceptible to corrosion on the hull and welding joints under marine environment. Here, we demonstrate the application of a novel multifunctional nano-metal-oxide mixture comprised of iron, titanium, and cerium as a marine coating to prevent corrosion. The electrochemical performance of nano-metal-oxide mixture coatings, applied over boat-building steel, was evaluated at $3.5 \% \mathrm{NaCl}$ medium. The nano-mixture surface coatings showed an efficient corrosion resistance with increased polarization resistance of $6043 \Omega \mathrm{cm}^{2}$ and low corrosion current density of $3.53 \times 10^{-6} \mathrm{~A} \mathrm{~cm}^{-2}$. The electrochemical impedance spectral data exhibited improvement in the polarization resistance of outermost surface and internal layers. The coating responded faster recovery to normal state when subjected to an induced stress over the coating. The nano-material in the coating behaves as a semiconductor; this enhanced electronic activity over the surface of the steel.
\end{abstract}

Keywords Marine corrosion $\cdot$ Nano-metal oxide $\cdot$ Corrosion protection $\cdot$ Electrochemical analysis

\section{Introduction}

Fishing forms the major livelihood activity to the sizeable population living in the coastal states of India. Commercial fishing activities are mainly carried out using the traditional wooden fishing canoes and mechanized boats. Recent years, steel is extensively used for construction of fishing boats due to the scarcity of the conventional boat-building timbers. Boats constructed with steel are having low maintenance cost and safer to operate longer fishing days in the sea. The recommended steel for the construction of fishing boat is BIS 2062-grade B steel. The major concerns regarding the steel fishing boats are the corrosion, which occurs in the hull and the welding joints. Micro-sized organic pigments

Electronic supplementary material The online version of this article (https://doi.org/10.1007/s13204-018-0650-y) contains supplementary material, which is available to authorized users.

P. Muhamed Ashraf

ashrafp2008@gmail.com

Fishing Technology Division, ICAR-Central Institute of Fisheries Technology, Matsyapuri PO, Cochin, Kerala 682 029, India are used for protecting marine structures from corrosion and are highly susceptible to coating defects, poor adhesion, low-impact resistance, optical transparency, abrasion and scratch resistance, lower coating flexibility, etc. The major disadvantage of polymeric coating is the pinholes and pores, through which the corrosive agents will penetrate leading to coating failures (Husain et al. 2013). To override the above problems, nano-sized materials have recently been used in paints and these paints have exhibited excellent efficiency improvements compared to the conventional coating formulations (Fernando 2004). Nano-oxides of Ti, Zn, Fe, Ca, Al, etc. are employed in the coatings recent years (Dhoke and Khanna 2009).

The conventional approaches towards the coating of steel materials with ceramic, polymeric, electrodeposition, etc., are effective to some extent in aggressive environments. Nano-materials provide an efficient corrosion resistance in self-assembled nano-phase particle, due to its high surface area and adhesion to the substrate (Voevodin et al. 2003; Bjerklie 2005). Three layer $\mathrm{TiO}_{2}-\mathrm{Al}_{2} \mathrm{O}_{3}$ nanocomposite coatings (Vaghari et al. 2011) and TiN-based coatings (Ilevbare and Burstein 2001) exhibited excellent corrosion resistance on SS316L. Not much work has been done to introduce a mixture consisting of multifunctional 
nano-sized inorganic metal oxides as coating material instead of one or two metal-oxide composites over carbon steel.

Rare-earth oxide, such as cerium oxide, has been widely used in solid-oxide fuel cells and as thermal and anti-corrosion barrier during high-temperature catalytic applications. Nano-sized cerium oxide incorporated in nickel, aluminium, and magnesium matrices improved the corrosion resistance and wear resistance (Arurault et al. 2004; Low et al. 2006; Chandrasekar and Pushpavanam 2008; Xue et al. 2010). A recent report showed the development of super-hydrophobic surface of magnesium alloys and aluminium alloys using nano-cerium-oxide thin films (Ishizaki et al. 2011; Liang et al. 2013). The commonly employed method to prevent corrosion in mild steel is to provide a permanent impermeable coating. Nanocerium oxide is used as inhibitor to reduce the corrosion in $\mathrm{H}_{2} \mathrm{SO}_{4}$ medium (Sharmila et al. 2013). Hydroxides and oxides of cerium and titanium composite coatings on 2024 aluminium alloy improved the adhesive strength, microhardness, and corrosion resistance. Higher concentration of cerium oxide has enhanced the barrier resistance and hence corrosion resistance (Han et al. 2012). A mixture of cerium-oxide and titanium-oxide-reinforced aluminium showed fouling and corrosion resistances (Ashraf and Shibli 2008).

Increased research interest was shown on $\mathrm{TiO}_{2}$ due to its unique physicochemical properties, excellent chemical stability, good photo-catalyst, and its ability to protect materials from UV radiation (Zheng et al. 2008; Dawidczyk et al. 2008; Woan et al. 2009). $\mathrm{TiO}_{2}$ has ability to switch the surface wettability between hydrophilicity and super-hydrophobic (Wang et al. 1997; Huang et al. 2014; Hoshian et al. 2015). Nano- $\mathrm{TiO}_{2}$ is an excellent cathodic inhibitor, photo-catalyst, an antimicrobial additive, and the antifouling agent in the marine environment (Lovern et al. 2007; Ashraf and Shibli 2008; Etacheri et al. 2015; Zhang et al. 2015). Zhang et al. (2015) studied the removal of humic acid through photodecomposition using $\mathrm{Fe}_{2} \mathrm{O}_{3}$ l $\mathrm{TiO}_{2}$ nano-wires. The mechanism explained is that $\mathrm{Fe}_{2} \mathrm{O}_{3}$ absorbs visible light and transfers the conduction band electron to the electron traps of anatase $\mathrm{TiO}_{2}$.

Nano- $\mathrm{Fe}_{2} \mathrm{O}_{3}$ is extensively used for magnetic storage devices, catalysis, targeted drug delivery, magnetic hypothermia, magnetic resonance imaging, and as biosensors (Yang et al. 2008; Laurent et al. 2011; Lee and Hyeon 2012; Cao et al. 2012). Not much work has been carried out using the above three metal oxide together for surface modification of steel. The present study aimed to understand the combined effect of multifunctional nano-oxides, viz., nano-iron oxide, nano-titanium oxide, and nanocerium oxide, on surface modification of boat-building steel.

\section{Materials and methods}

The nano-titanium oxide (4-8 nm, anatase phased and $\mathrm{HNO}_{3}$ stabilized) and iron-oxide $\mathrm{Fe}_{2} \mathrm{O}_{3}(4-8 \mathrm{~nm}, 5 \%$ aqueous suspension) were purchased from Reinste Nano Ventures India Ltd. Nano-cerium oxide (30-45 nm) was prepared in the laboratory as per the procedure described by Fu et al. (2005). Carbon steel BIS 2062-grade B was procured from Kerala State Inland Navigation Corporation, Cochin, India and the composition are as follows. Carbon $0.22 \%, \mathrm{Mn} 1.5 \%, \mathrm{Si}$ $0.4 \%, \mathrm{P} 0.045 \%$, and $\mathrm{S} 0.045 \%$ and the rest is iron. Dimethyl formamide is purchased from $\mathrm{CDH}$ Mumbai, India. All the chemicals were used as received without any purification.

\section{Preparation of specimen}

The steel samples were cut into $3 \times 5 \mathrm{~cm}$ sizes and pickled using $5 \% \mathrm{H}_{2} \mathrm{SO}_{4}$ for $3 \mathrm{~min}$, washed with Milli Q type 1 water, and allowed to dry in the air. Then, the specimens were polished up to 1000 grits using a series of silicon carbide papers ranging from 300 to 1000 grits. Degreased the specimen by sonication for $30 \mathrm{~min}$ in acetone and then with water. The specimen is kept in the desiccators until the treatment. The nano- $\mathrm{Fe}_{2} \mathrm{O}_{3}, \mathrm{CeO}_{2}$, and $\mathrm{TiO}_{2}$ mixtures were dispersed in dimethyl formamide as per the details given in Table 1. The suspension was sonicated for $1 \mathrm{~h}$ and decanted to remove solid residues. $30 \mu \mathrm{l}$ of the mixtures of the solutions were pipetted over the specimen and spread using glass slides. Allowed to dry under infrared lamp. The process was repeated for three times on both sides of the specimen and finally kept at $100{ }^{\circ} \mathrm{C}$ in an air oven for $1 \mathrm{~h}$. Removed, wrapped with dry tissue paper, and kept in a zipper bag. The specimens were kept in the desiccators until the analysis.

\section{Electrochemical evaluation}

The linear sweep voltammetric (LSV) analysis of surface modified specimen was done using Metrohm PGstat $302 \mathrm{~N}$

Table 1 Details of treatments of nano- $\mathrm{Fe}_{2} \mathrm{O}_{3}, \mathrm{TiO}_{2}$, and $\mathrm{CeO}_{2}$ for surface modification boat-building steel BIS 2062

\begin{tabular}{llll}
\hline \multirow{2}{*}{$\begin{array}{l}\text { Treatment } \\
\text { symbol }\end{array}$} & \multicolumn{2}{l}{ Concentration of nano-metal oxides } \\
\cline { 2 - 4 } & Iron oxide & Cerium oxide & Titanium oxide \\
\hline F0 & 0 & 0 & 0 \\
F1 & 0.005 & 0.005 & 0.005 \\
F2 & 0.01 & 0.01 & 0.01 \\
F3 & 0.005 & 0.01 & 0.01 \\
F4 & 0.01 & 0.005 & 0.005 \\
F5 & 0.005 & 0.01 & 0.005 \\
F6 & 0.01 & 0.01 & 0.005 \\
\hline
\end{tabular}


with FRA. 3.5\% (wt/vol) $\mathrm{NaCl}$ is used as an electrolyte, $\mathrm{Pt}$ as counter electrode, $\mathrm{Ag} / \mathrm{AgCl}(3 \mathrm{M} \mathrm{KCl})$ as reference electrode, and specimen with exposed area of $1 \mathrm{~cm}^{2}$ as working electrode. The specimen was kept in the electrolyte for $1 \mathrm{~h}$ to stabilize the OCP. The LSV was carried out with a scan rate of $0.001 \mathrm{~V} \mathrm{~s}^{-1}$. Tafel slope analysis was done using the Nova software. The electrochemical impedance spectra of the surface-modified steel specimen were done in $3.5 \% \mathrm{NaCl}$ with $\mathrm{Pt}, \mathrm{Ag} / \mathrm{AgCl}(3 \mathrm{M} \mathrm{KCl})$, and sample, respectively, as a counter, reference, and working electrode. The specimens were scanned from $100 \mathrm{kHz}$ to $0.1 \mathrm{~Hz}$ at 60 decades after 30 min immersion in the electrolyte. The generated EIS data were fitted with simple Randle's equivalent circuit model. All the analyses were repeated at least four times and the average was used for discussion.

Corrosion rates on the surface-modified steel samples were analyzed by a weight loss method as per the ASTM G1. The pre-weighed specimen was immersed in $3.5 \% \mathrm{NaCl}$ for 40 days under room temperature $28 \pm 3{ }^{\circ} \mathrm{C}$. The specimen was removed after the experiment, washed with water, and sonicated to remove adsorbed dirt for $20 \mathrm{~min}$. Dried in an air oven at $100{ }^{\circ} \mathrm{C}$ for $30 \mathrm{~min}$ and allowed to cool in a desiccator. The final weight was recorded and calculated the corrosion rate using the formula $\mathrm{CR}=534 \mathrm{~W} / D A T$, where $W$ is the weight loss, $D$ is the density, $A$ is the area in square inch, and time in hours.

\section{Surface characterization}

The steel specimen of $0.5 \times 0.5 \mathrm{~cm}$ was polished using a series of silicon carbide papers up to 2000 grits, degreased using acetone, and washed with water. Surface modification of the specimen was carried out by pipetting $2 \mu \mathrm{l}$ of nano-material as described earlier. Surface topography of the steel was analyzed under non-contact mode using Park XE 100 AFM. The Si scanning probe with tip radius of less than $10 \mathrm{~nm}$ was used. The data were processed using the XEI software. The microstructure of the specimen was analyzed using JEOL Model JSM-6390LV SEM.

\section{Results and discussion}

\section{Nature of corrosion products}

The nature of corrosion products formed over boat-building steel under atmospheric and 3.5\% $\mathrm{NaCl}$ environment was compared with the nano-iron oxide using spectrophotometry (Fig. 1). The corrosion product formed in all the three cases was almost similar in the UV region at 192,280, and $380 \mathrm{~nm}$. In the visible region, a peak at around $480 \mathrm{~nm}$ was recorded in all the cases. $\mathrm{Fe}_{2} \mathrm{O}_{3}$ exhibits three types of electronic transitions viz. $d-d$ orbital transitions linked with $\mathrm{Fe}^{3+}$ ions, $\mathrm{O} 2 p-\mathrm{Fe} 3 d$ ligand to metal charge transfer, and pair excitations coupled with 2 neighboring $\mathrm{Fe}^{3+}$ cations. Ligand-to-metal charge transfer $(\mathrm{O} 2 p-\mathrm{Fe} 3 d$ ) bands exist in the region of 440-800 nm (Pailhe et al. 2008; Gaudon et al. 2010).

\section{Microstructure analysis}

Clean the surface of the steel specimen was coated individually with nano-iron oxide, nano-titanium oxide, nano-cerium oxide, and the mixture of three metal oxides (3MO) to study the surface characteristics. The surface topography of the specimen is analyzed using AFM and is shown in Fig. 2.
Fig. 1 Spectrophotometric evaluation of nano- $\mathrm{Fe}_{2} \mathrm{O}_{3}$ and corrosion products formed over the boat-building steel due to air exposure and $3.5 \% \mathrm{NaCl}$ exposure

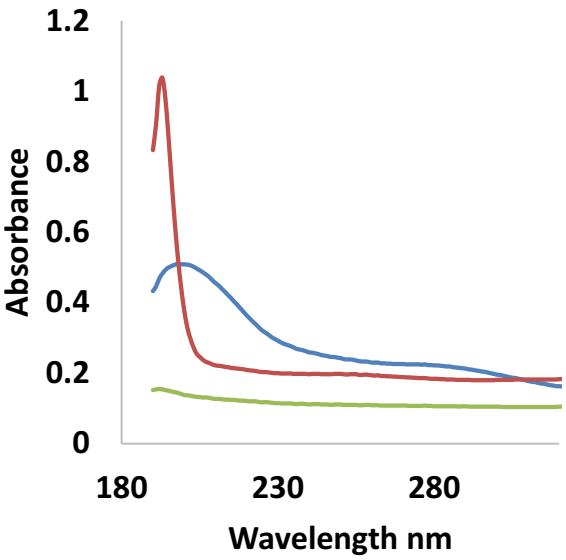

Nano iron oxide

Corrosion product formed in $\mathrm{NaCl}$

Corrosion product formed in water

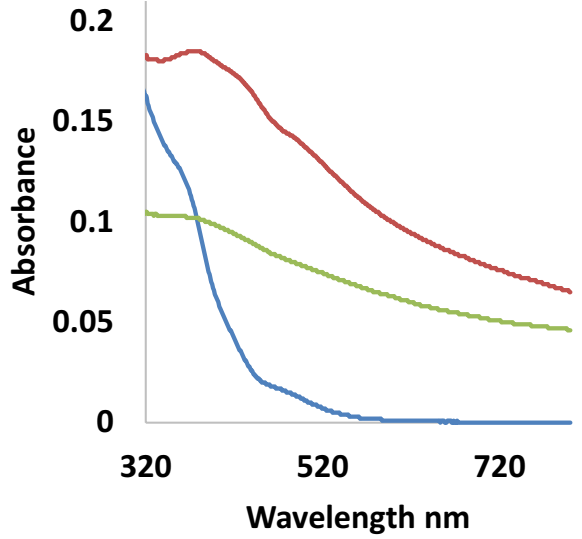

Nano iron oxide Corrosion product formed in $\mathrm{NaCl}$

Corrosion product formed in water

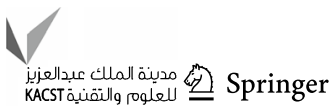


Fig. 2 AFM topography of nano-metal oxide and $3 \mathrm{MO}$ coated steel
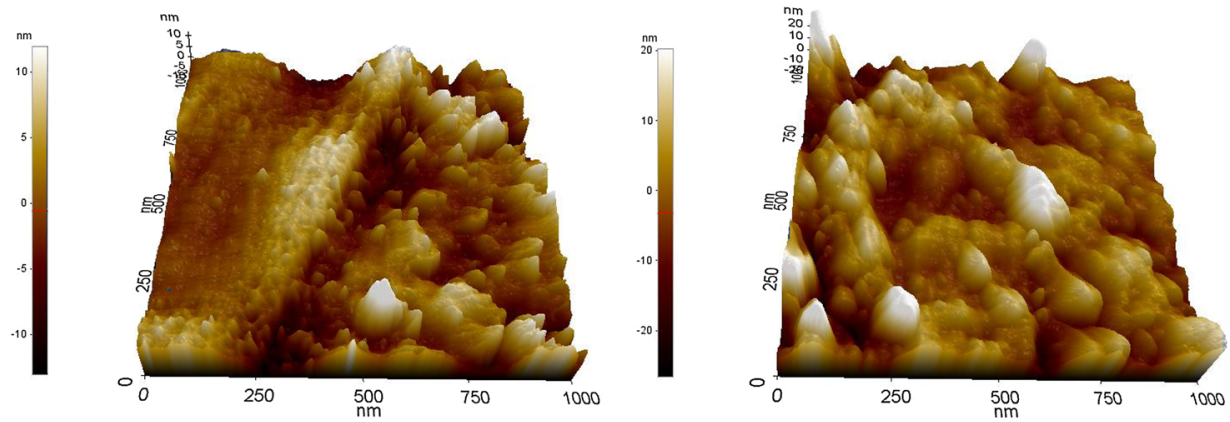

Untreated bare steel
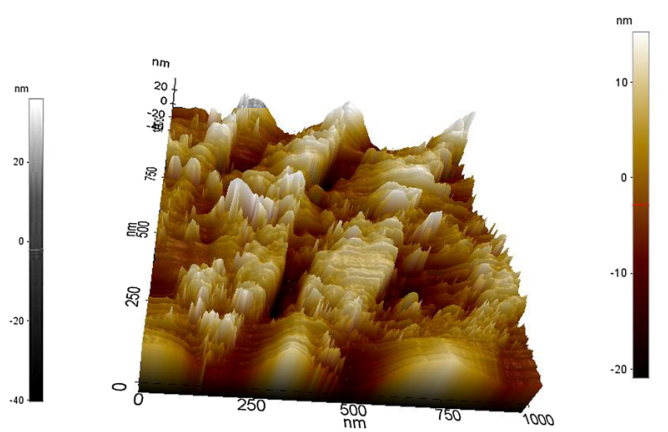

$\mathrm{CeO}_{2}$ coated steel

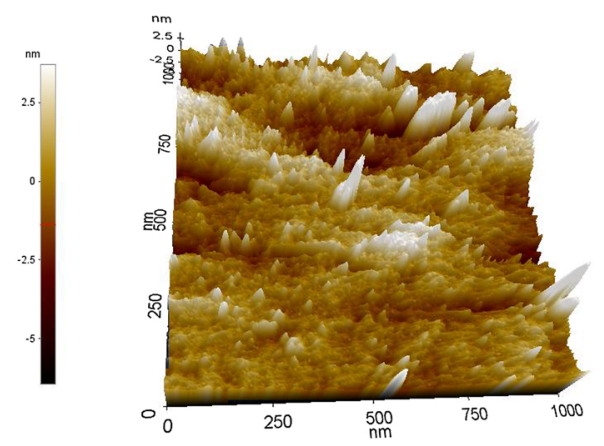

$\mathrm{Fe}_{2} \mathrm{O}_{3}, \mathrm{TiO}_{2}$ and $\mathrm{CeO}_{2}$ mixture coated steel
$\mathrm{Fe}_{2} \mathrm{O}_{3}$ coated steel

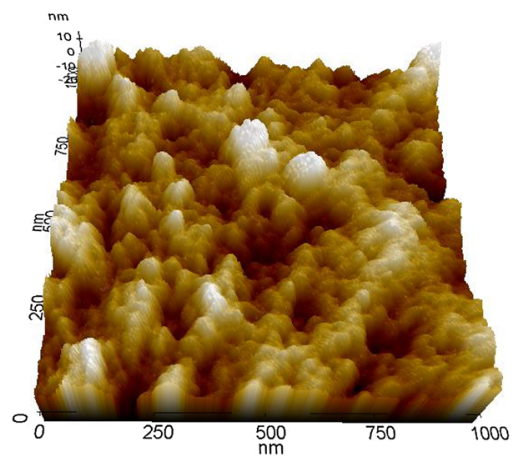

$\mathrm{TiO}_{2}$ coated steel
The surface topography of the steel surface exhibited that the coatings were uniformly distributed and adhered over the substrate and the grain boundaries of the steel surface were fully covered by the nano-materials. Higher surface area and adhesiveness over the substrate are characteristics of nano-materials (Voevodin et al. 2003; Bjerklie 2005). A line profile drawn on the $1000 \mathrm{~nm}$ AFM micrograph and the results of average surface roughness $\left(R_{\mathrm{a}}\right)$ and root mean square roughness $\left(R_{\mathrm{q}}\right)$ are shown in Fig. 3. $R_{\mathrm{a}}$ highlights the general height variations in the surface and $R_{\mathrm{q}}$ are the root mean square average of the roughness profile ordinates. The order of roughness was nano-cerium-oxide coated $>$ nano-iron oxide $>$ nano-titanium oxide $>$ bare steel $>$ 3MO-coated steel. The nano-metal oxides were occupied in the steel surface uniformly with the lowest surface roughness, indicating that the grain boundaries were sealed completely by the $3 \mathrm{MO}$.

The scanning electron micrographs of untreated steel F0, 3MO-coated steel F4 and F5 are shown in Fig. 4. The nano-3MO particles were uniformly distributed on the steel substrate and the particles were occupied over the grain boundaries. The results were comparable with AFM topographic images. This shows that the $3 \mathrm{MO}$ was strongly and uniformly adhered over the surface of steel. 


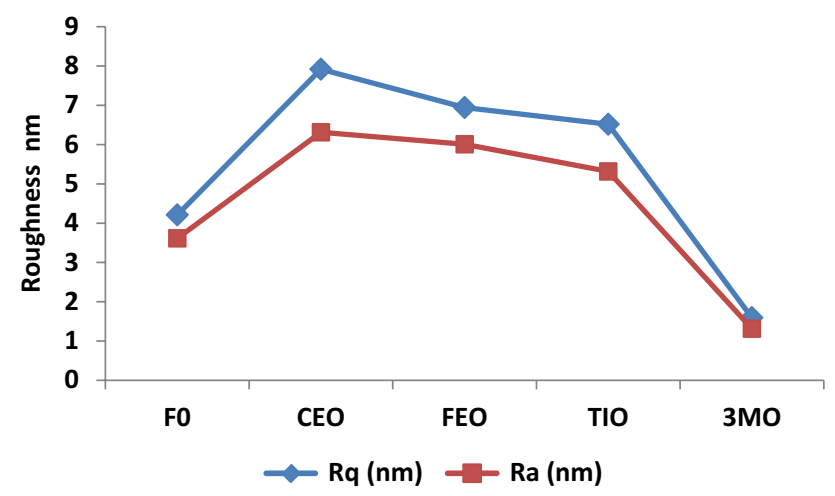

Fig. 3 Average roughness $\left(R_{\mathrm{a}}\right)$ and root mean square roughness $\left(R_{\mathrm{q}}\right)$ of untreated $\mathrm{F} 0$, nano- $\mathrm{CeO}_{2}$, nano- $\mathrm{Fe}_{2} \mathrm{O}_{3}$, nano- $\mathrm{TiO}_{2}$, and $3 \mathrm{MO}-$ coated steel

\section{Electrochemical evaluation}

The electrochemical characteristics of the surface-modified steel specimens were studied using linear sweep voltammetric analysis. Tafel plots of all the 3MO-coated boatbuilding steel specimens are shown in Supplementary file as Fig S1. The linear sweep voltammetric parameters are shown in Fig. 5. The corrosion potential $E_{\text {corr }}$, corrosion current density $I_{\text {corr }}$, and polarization resistance $R_{\mathrm{p}}$ were ranged, respectively, from $-0.753 \pm 0.065$ to -0.613 $\pm 0.030 \mathrm{~V}, 3.353 \times 10^{-6} \pm 1.47 \times 10^{-6}$ to $3.59 \times 10^{-5} \pm$ $4.85 \times 10^{-5} \mathrm{~A} \mathrm{~cm}^{-2}$, and $1961 \pm 980$ to $6043 \pm 2562 \Omega \mathrm{cm}^{2}$.
The lowest polarization resistance and higher corrosion current density showed by the specimen coated with $0.005 \%$ each of $\mathrm{Fe}_{2} \mathrm{O}_{3}, \mathrm{TiO}_{2}$, and $0.01 \% \mathrm{CeO}_{2}$. The surface coating with 1:1:1 ratio of $3 \mathrm{MO}$ showed the highest $I_{\text {corr }}$ and thereby increased corrosion. When $\mathrm{Fe}_{2} \mathrm{O}_{3}$ concentration increased from 0.005 to $0.010 \%$ in $3 \mathrm{MO}$ mixture, the specimen showed decreased corrosion resistance. Whereas nano- $\mathrm{CeO}_{2}$ concentration increased from 0.005 to $0.01 \%$ in $3 \mathrm{MO}$ mixture, the specimen showed higher corrosion resistance. In the case of $\mathrm{F} 6$ the increased $\mathrm{Fe}_{2} \mathrm{O}_{3}$ and $\mathrm{TiO}_{2}$ contents in the $3 \mathrm{MO}$, the specimen showed a decrease in the polarization resistance. This indicates the concentration of $\mathrm{Fe}_{2} \mathrm{O}_{3}$ and $\mathrm{TiO}_{2}$ has an important role in the corrosion resistance of the $3 \mathrm{MO}$-coated specimen. The optimum concentration $\mathrm{CeO}_{2}$ was $0.01 \%$ and its further increase was shown with lower polarization resistance indicating the higher corrosion. Further to check, the impact of higher concentration (double and triple times) by maintaining the same ratios as in F5 showed not much improvement in corrosion resistance (results not shown in the manuscript). Hence, the optimum ratio with maximum efficiency was 0.005:0.01:0.005 of $\mathrm{Fe}_{2} \mathrm{O}_{3}, \mathrm{CeO}_{2}$, and $\mathrm{TiO}_{2}$. Increased concentration of nano- $\mathrm{CeO}_{2}$ in the surface enhanced the barrier resistance and hence corrosion resistance (Han et al. 2012).

There was no significant difference between the $E_{\text {corr }}$ values between the treatments. The values were about $\pm 0.075 \mathrm{~V}$ than untreated specimen. In general, the corrosion resistance was cathodic in nature (Bethencourt et al. 2004). The cathodic shift was mainly due to the
Fig. 4 Scanning electron micrographs of bare-steel specimen and 3MO-coated specimens (F4 and F5)
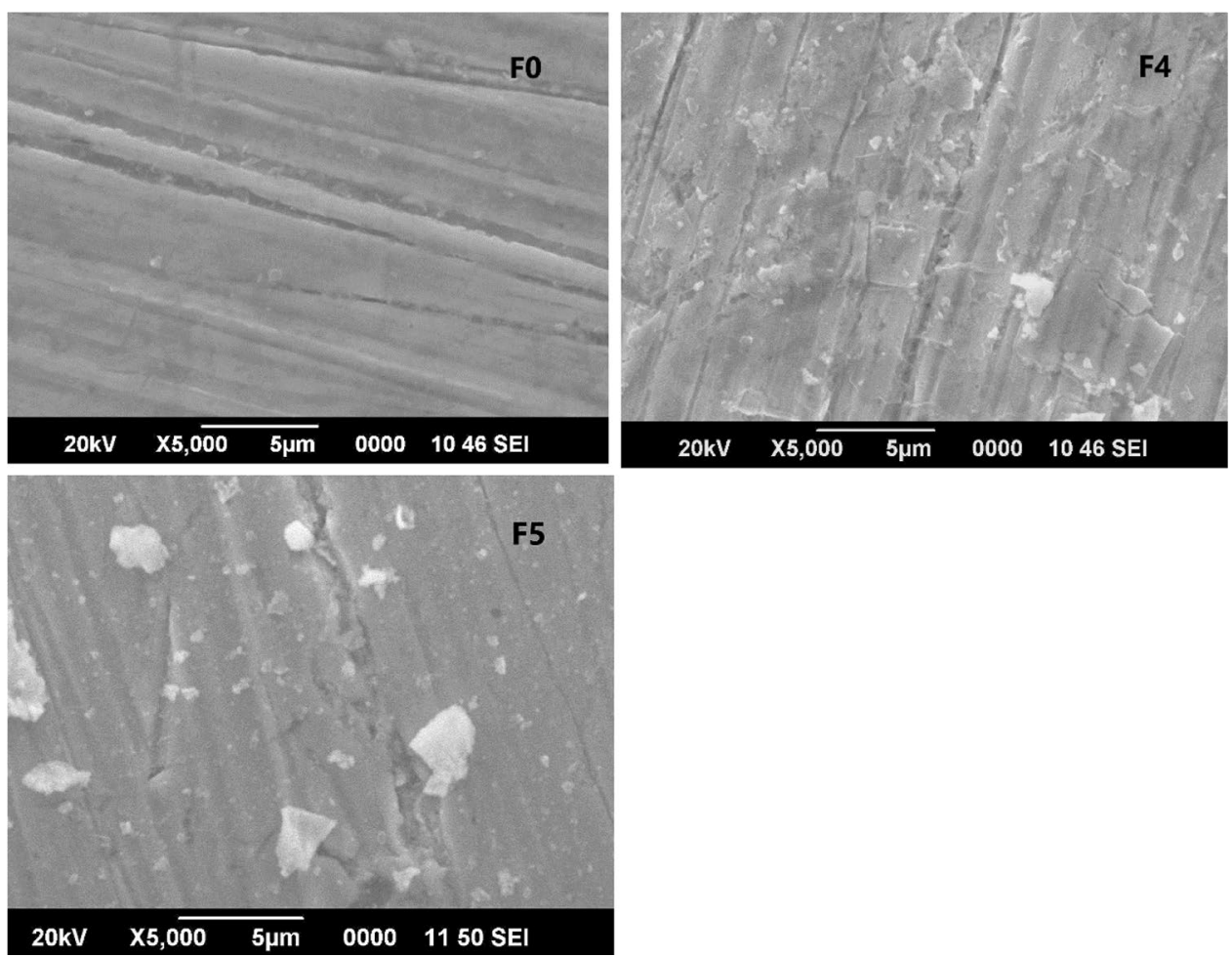
Fig. 5 Linear sweep voltammetric data of three metal-oxide mixture-coated boat-building steel
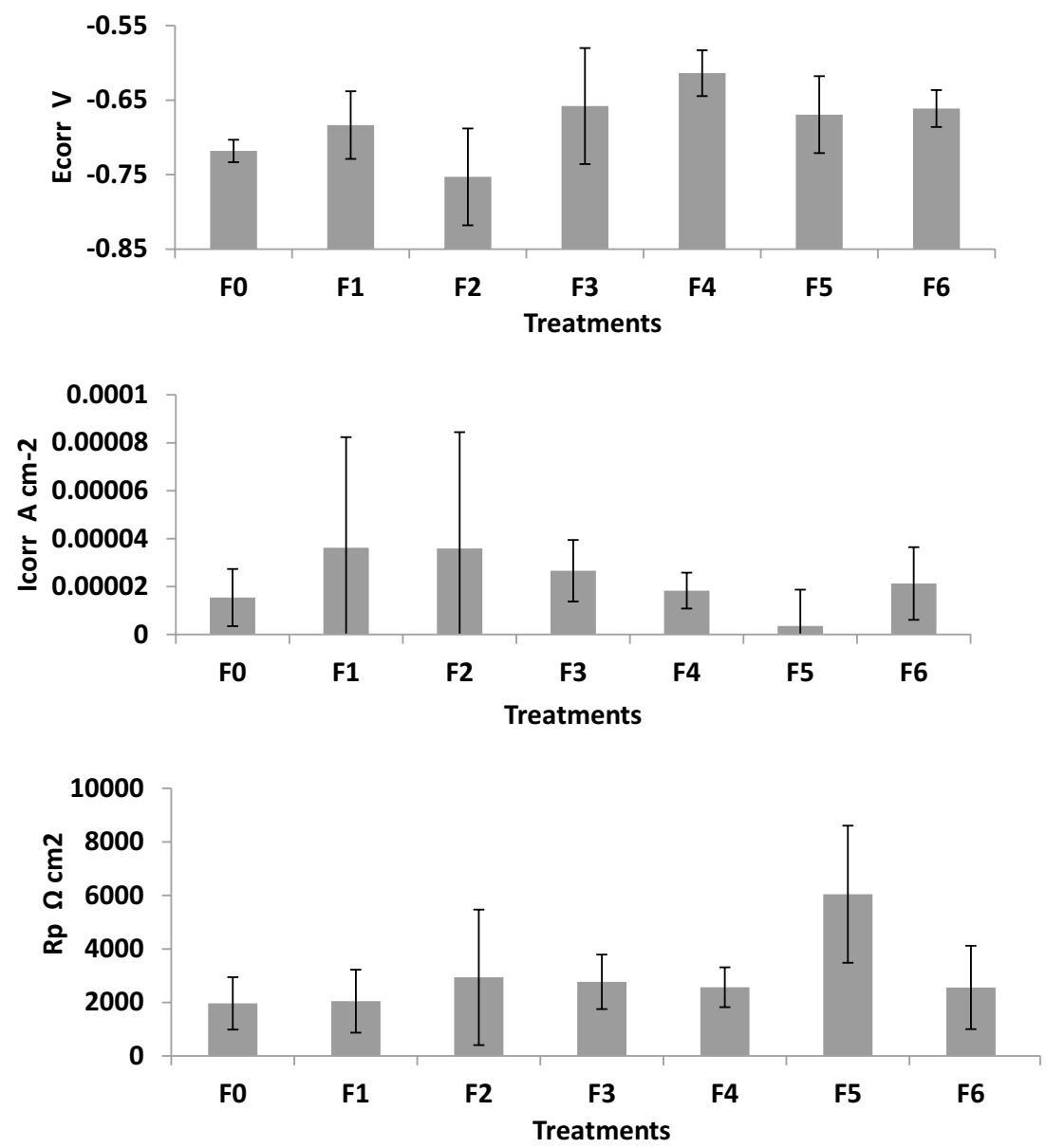

increased concentration of nano-cerium oxide. Here, the Tafel plot showed a longer plateau immediately after the corrosion potential. The plateau of the Tafel curve was due to the influence of $\mathrm{CeO}_{2}$ in the matrix (Hasannejad et al. 2013). The similar behaviour was noted earlier studies on aluminium incorporated with cerium oxide (Ashraf and Shibli 2007). The treatment F5 with the highest polarization resistance highlights the coating formed over the steel matrix smoother with the lowest roughness (Hasannejad et al. 2013). This was further correlated with the results of AFM studies. Based on corrosion current density, the corrosion inhibition efficiency was about $40 \%$.

\section{EIS studies}

The Nyquist plots of the 3MO-coated steel after immersing $30 \mathrm{~min}$ in $3.5 \% \mathrm{NaCl}$ are shown in Fig. 6. For estimating the EIS parameters quantitatively, the data are fitted with simple Randle's equivalent circuit model and the results are shown in Fig. 7. The constant phase element (CPE) was used instead of capacitance in this study. $R_{\mathrm{p}}$ in the high-frequency (HF) and low-frequency (LF) regions were ranged from $9.21 \pm 6.54$ to $93.08 \pm 44.94 \Omega \mathrm{cm}^{2}$
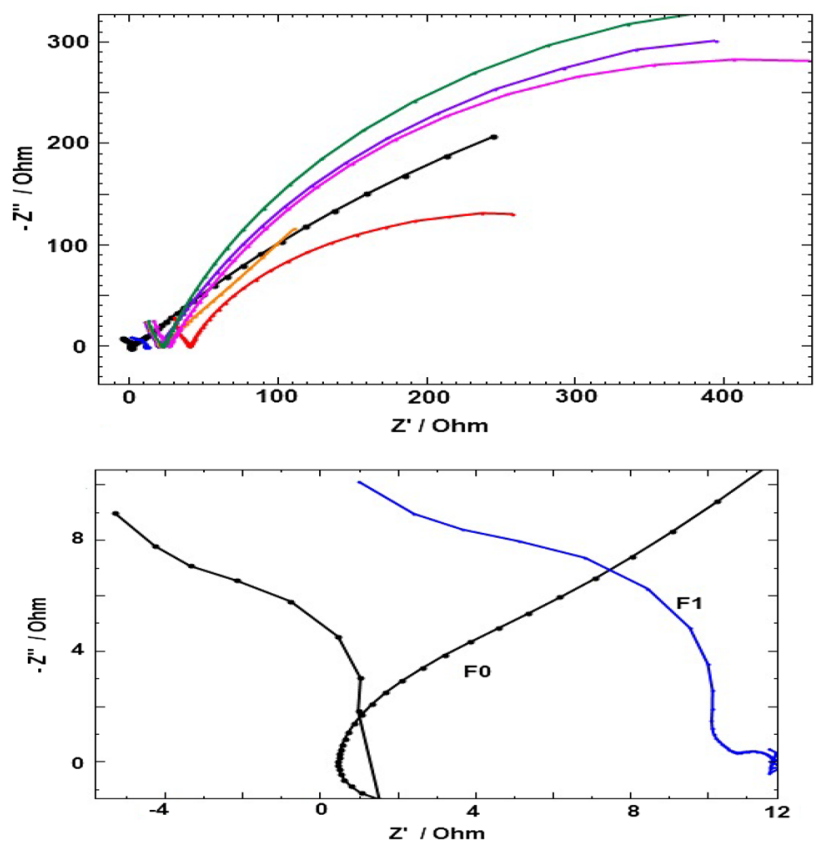

Fig. 6 Nyquist plots of 3MO-coated steel. a F0-F6 combined plots and $\mathbf{b} \mathrm{F} 0$ and $\mathrm{F} 1$ alone 
Fig. 7 EIS parameters after fitted with simple Randle's equivalent circuit model
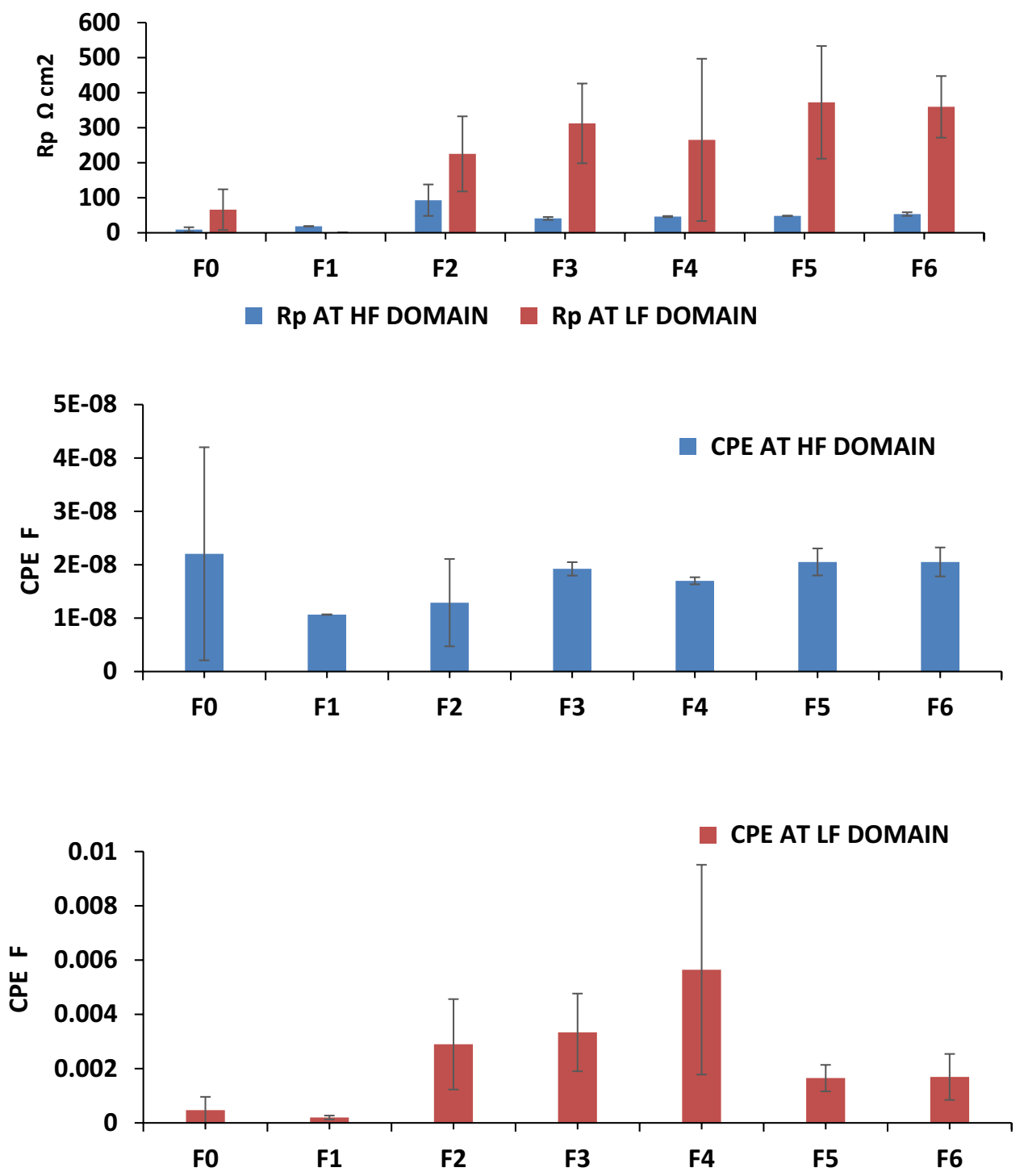

and $1.13 \pm 0.09$ to $372.25 \pm 160.77 \Omega \mathrm{cm}^{2}$, respectively. The CPE in the HF and LF regions was, respectively, ranged from $1.09 \times 10^{-8} \pm 5.26 \times 10^{-11}$ to $2.21 \times 10^{-8} \pm 2.00 \times 10^{-8} \mathrm{~F}$ and $1.98 \times 10^{-4} \pm 7.32 \times 10^{-5}$ to $5.64 \times 10^{-3} \pm 3.86 \times 10^{-4} \mathrm{~F}$, respectively. There are three types of Nyquist plots which were shown by the specimens with different treatments. The untreated control exhibited the Nyquist plot with clear HF and LF domains and both partially overlapped each other (merged) in the middle. The bare steel specimen always has a thin layer of iron oxide and this prevents the interaction of surface with the mild atmospheric corrosives. The merger of HF and LF domains in the Nyquist plots highlights that the thin films of native iron oxide have strong interaction with internal layers and hence higher polarization resistance in the HF domain. The smaller LF domain and lowest polarization resistance indicated the instability of the internal layer in $3.5 \% \mathrm{NaCl}$ medium. The treatment F1 showed a typical Nyquist plot with independent wider HF and smaller LF domains (Type II). This inferred that the $3 \mathrm{MO}$ forms a barrier protection, but the internal layer was highly unstable. Type II plots indicate that $\mathrm{Fe}_{2} \mathrm{O}_{3}-\mathrm{TiO}_{2}-\mathrm{CeO}_{2}(1: 1: 1)$ form a strong barrier in the outermost region, but it is highly susceptible to degradation under aggressive corrosive marine environment. In the case of F1, $R_{\mathrm{p}}$ in the LF domain was significantly lower, indicating the instability of the internal layer. A similar situation was common in pure aluminium, where aluminium oxide exhibits stronger oxide layer on the surface, but under aggressive environments, it will not resist the stress and, hence, undergo corrosion (Ashraf and Shibli 2007). Here, the equal concentration $3 \mathrm{MO}$ form good protective layer probably resists the penetration of electrolyte. This layer was stronger than native $\mathrm{Fe}_{2} \mathrm{O}_{3}$ layer formed over the bare metal. The surface coating may not withstand under the aggressive $\mathrm{NaCl}$ environment and this was further correlated with the results of LSV studies. The surface has higher amounts of 
electrons from the oxides of $3 \mathrm{MO}$ and the mechanism was discussed in later sections.

These Nyquist plots of F2-F6 were classified as Type III plots. The Nyquist plots showed partial semicircle in the HF domain (Fig. 6). Type III plots showed two independent wider HF and LF domains. The polarization resistance in $\mathrm{HF}$ and LF domains was significantly higher than the bare metal, F0, highlighting the improved surface and internal layers due to the nano-3MO coating. This ensures higher corrosion protection of the steel due to the nano-3MO coating. The lowest CPE values in F5 highlight that the coating prevents the uptake of electrolyte to the internal layers, which further prevented corrosion. The coating helps to introduce longer layer capillary paths in the thin film for the approach of electrolytes or corrosive ions to the substrate (Fig. 8). The straight-line slope of the Bode plots (not given in the paper) showed that the coating formed over the steel seldom allowed to penetrate the electrolytes. Probably, occupying the nano-particles in the channels or pores blocked the transport or diffusion of electrolytes from the surface to the internal layers. This highlights the integrity of the coatings and enhanced corrosion protection (Yeh et al. 2006; Lamaka et al. 2008; Domínguez-Crespo et al. 2009). In F1, the 3MO was in 1:1:1 ratio with the lowest concentration of oxides and these oxides occupy the pores of native iron-oxide layer which led to the total closure of the path layer. This led to the instability in the intersection of steel and 3MO layer evidenced by the two separate HF and LF domains with wider gap. Hence, lower polarization resistance increased corrosion.

\section{Corrosion rate}

Pre-weighed surface-modified specimens were exposed in $3.5 \% \mathrm{NaCl}$ for 40 days and corrosion rates were calculated as per the ASTM G1. The results are shown in Fig. 9. The corrosion rates were ranged from $1.7 \times 10^{-3}$ to $2.5 \times 10^{-3}$ mils per year. The specimen having $0.005 \% \mathrm{Fe}_{2} \mathrm{O}_{3}, 0.005 \% \mathrm{TiO}_{2}$, and $0.01 \% \mathrm{CeO}_{2}$ exhibited lowest corrosion rate. The results
Fig. 8 Pictorial representation of steel and coated surface based on three types of Nyquist plots
Fig. 9 Corrosion rates of 3MOcoated steel
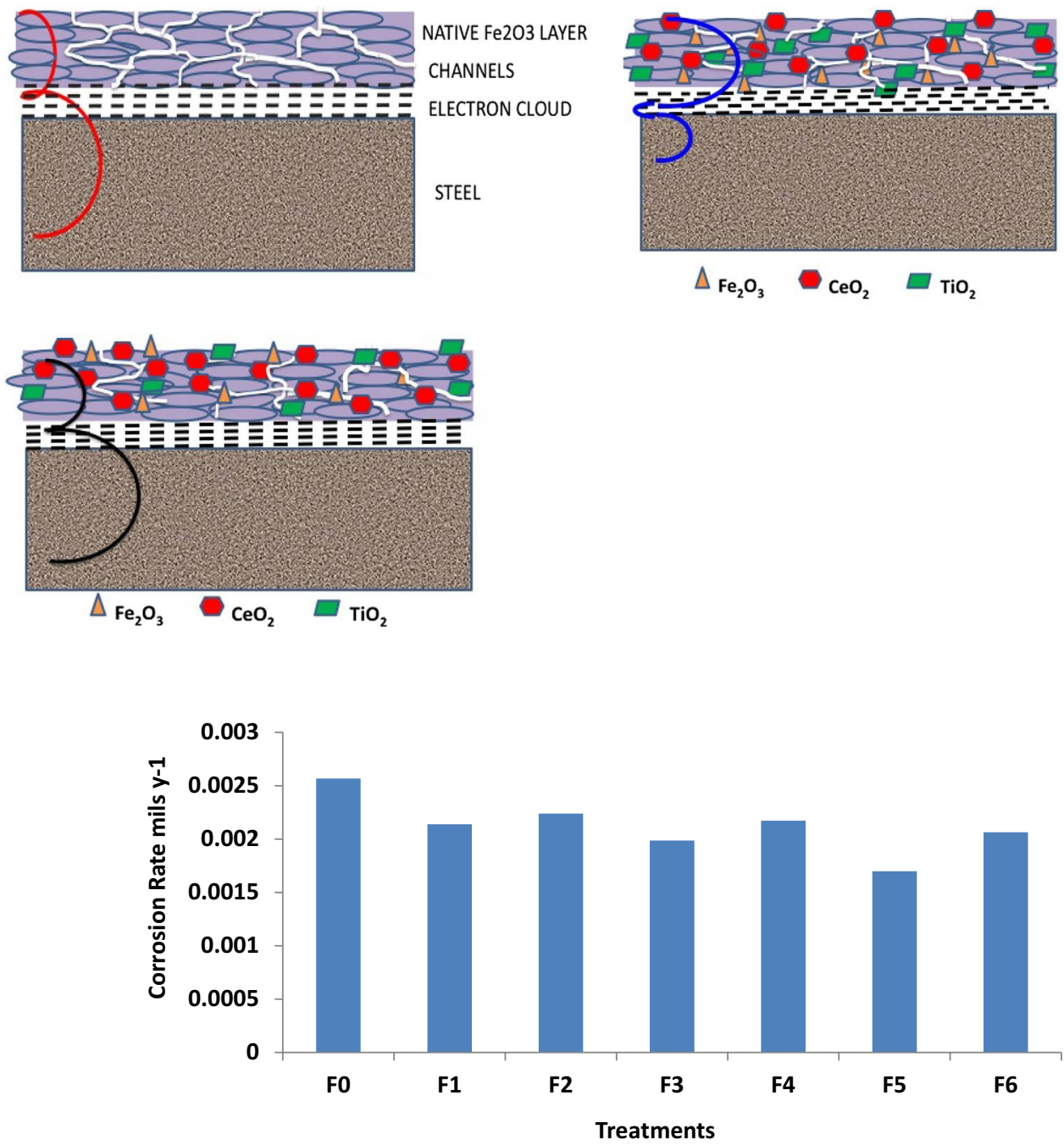
correlated with the findings of LSV, EIS, and AFM studies. The treatment showed 35\% more efficient than control.

\section{Stress healing}

To study the response of the steel if scratched under marine environments, the fishing boats undergo a series of rubbing and scratching during berthing in the shore. The $3 \mathrm{MO}$ surface-modified specimen $\mathrm{F} 5$ was immersed in the $3.5 \% \mathrm{NaCl}$ for $24 \mathrm{~h}$ to stabilize the OCP in $3.5 \% \mathrm{NaCl}$. Next day, a deep scratch was made over the specimen using a sharp stainless steel knife. Changes in open-circuit potential (OCP) before and after the scratch are noted and are shown in Fig. 10. The system has shown increased OCP immediately after the scratch, but regained to the original form within $1 \mathrm{~min}$. The untreated specimen took more than 4 min to reach the stable OCP value. This shows that the healing stress was improved due to the surface treatment of $3 \mathrm{MO}$ over the boat-building steel.

\section{Mechanism of resistance to corrosion}

The native $\mathrm{Fe}_{2} \mathrm{O}_{3}$ present over the outermost layer of the steel probably behaving like a semiconductor due to the nano-metal-oxide treatment. The bandgap for $\mathrm{Fe}_{2} \mathrm{O}_{3}, \mathrm{TiO}_{2}$, and $\mathrm{CeO}_{2}$, respectively, was $2.2,3.2$, and $2.76 \mathrm{eV}$. The conduction band was $0.73,-0.25$, and -0.32 and valence band was $2.93,2.91$, and $2.44 \mathrm{~V}$, respectively, for $\mathrm{Fe}_{2} \mathrm{O}_{3}$, $\mathrm{TiO}_{2}$, and $\mathrm{CeO}_{2}$. The conduction band of the internal layer of the steel was either partially filled or overlapped with valence band; hence, there was no bandgap [http://web.ift. uib.no/AMOS/PHYS208/larsP-N/p-n-slide-lars.pdf (viewed on 30-7-2016)]. The partially filled electron or band in the layer moves the next higher energy levels; hence, the current conduction occurs easily. The outermost layer of steel, native $\mathrm{Fe}_{2} \mathrm{O}_{3}$, and conductivity were increased due to the doping of $3 \mathrm{MO}$ in the surface. The $3 \mathrm{MO}$ treatment over the surface of steel will make the surface behave as a semiconductor.
The bonding in metal-oxide semiconductors is different from the valence electrons of oxygen which are partially or fully transferred to the metal ion. Hence, metal oxides are highly ionic in nature. $\mathrm{Fe}_{2} \mathrm{O}_{3}$ and $\mathrm{TiO}_{2}$ have $3 d$ orbital from metal atoms of $\mathrm{Fe}$ and $\mathrm{Ti}$ and $2 p$ from oxygen. The $d$ orbital contributes more towards conduction band and $\mathrm{p}$ orbital towards the valence band (Fujishima and Honda. 1972; van de Krol. 2012). 3d orbital of transition metal is generally shrunken state and exhibits lesser overlap compared to $s$ and $p$ orbitals. The free holes in the valence band form polarons through electrostatic interaction with surrounding oxygen ions. The charge transfer through polarons plays an important role in $\mathrm{Fe}_{2} \mathrm{O}_{3}$ and $\mathrm{TiO}_{2}$. The oxygen vacancies of $\mathrm{Fe}_{2} \mathrm{O}_{3}$ located in the below the conduction band and it was partly responsible for the intrinsic $n$-type semi-conductivity. When the 3MO-coated layer interacts with the aqueous environment, the hydroxylation occurs. This mainly depends on the $\mathrm{pH}$ of the solution. Specific adsorption of $\mathrm{H}^{+}$or $\mathrm{OH}^{-}$species affects the charge distribution and potential distribution in the liquid-coating interface. The high electrochemical environment, the electrons, exists initially in the traps and inter-band states are emptied to fill the holes. Hence, a decrease in the electron density in the film and charge separation between the valence and conduction bands was facilitated. This results in a decrease electron-hole transport and competition with hole transport. Finally, long-lived photo-generated holes accumulated near the surface and this promotes oxidation of water (Barroso et al. 2013). Similar mechanism was explained in the case of nano-titanium oxide (Tang et al. 2008; Cowan et al. 2010). This shows that both iron oxide and titanium actively involve the photo-oxidation of water which results in deterrence microorganisms in the vicinity of the surface results a maximum corrosion protection. This might be the reason the black layer formed over the treated specimen.

The conduction band of $\mathrm{CeO}_{2}$ was a $\mathrm{Ce} 4 f$ band. Cerium ions are known to exhibit variable valency from $\mathrm{Ce}^{4+}$ to $\mathrm{Ce}^{3+}$ ions. The electrons in the cerium-oxide molecules behave as small polarons and oxygen vacancy defect were
Fig. 10 Open-circuit potential variation when stress was applied over untreated control and 3MO-treated steel

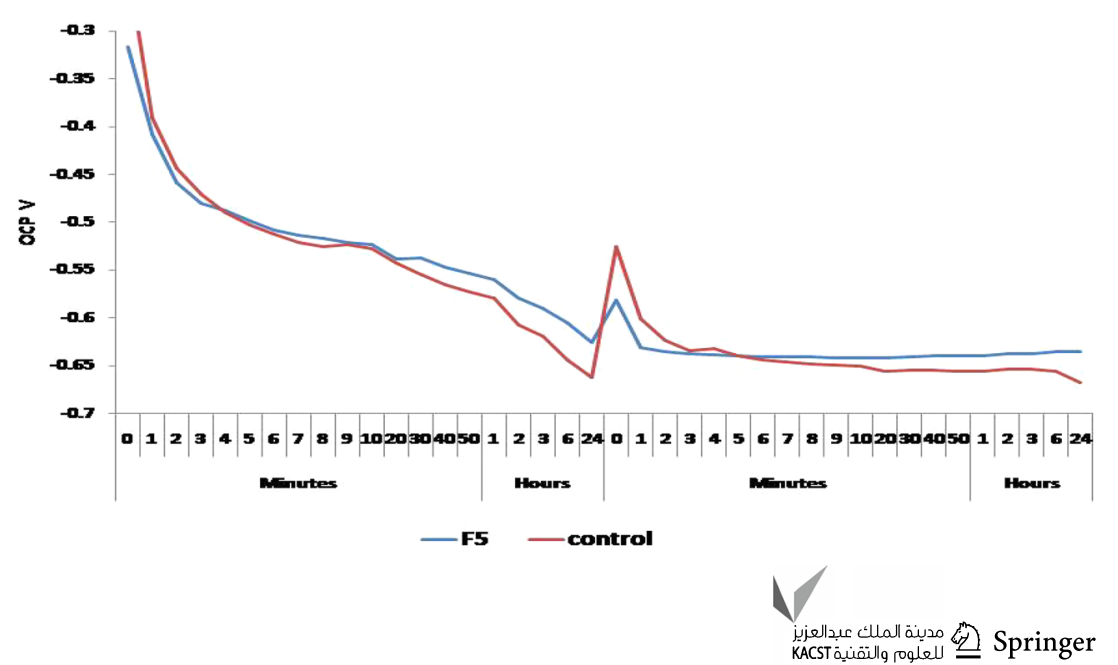


dominated in the chemical and electronic properties. These oxygen vacancies are mobile and contributed to the oxygen ion transport in the solid solutions (Campbell and Peden 2005; Zhang et al. 2009; Macedo et al. 2010). Oxygen storage capacity of cerium oxide helps to change the oxidation states and this was due to the nearly equal energy of $4 f$ and $3 d$ orbitals. This will help to distribute the electron density between the $f$ and $d$ orbitals (Holgado et al. 2000). The oxygen vacancy defect formation will decrease the oxygen content in the cerium oxide. Cerium oxide also acts as excellent oxygen buffers due to their redox capacity (Chen et al. 2006). The valence and defect structure of $\mathrm{CeO}_{2}$ is dynamic and may change with physical parameters like surface stress (Sheldon and Shenoy 2011). Redox process was prominent in $\mathrm{CeO}_{2}$ under an electrical field (Deshpande et al. 2005). The electrochemical behaviour of $\mathrm{CeO}_{2}$ based space charge models showed that the defect formation energies are different from bulk material. This results in an electrical gradient in the surface to maintain the thermodynamic equilibrium. Thermodynamic equilibrium changes with variation in stress and strain due to point defects and related volume changes (Sheldon and Shenoy 2011). Nano- $\mathrm{CeO}_{2}$ particles exhibit increased oxygen vacancies as the size of the particle decreases (Tsunekawa et al. 1999; Deshpande et al. 2005). The oxygen vacancy formation energy in $\mathrm{CeO}_{2}$ is lower in nano-sized $\mathrm{CeO}_{2}$ particles. It has higher electronic conductivity (Chiang et al. 1996, 1997). The mechanism probably is the large volume of holes created by nano-cerium oxide; this has facilitated the continuous flow of electron transport between the native $\mathrm{Fe}_{2} \mathrm{O}_{3}$ and internal layer. This has prevented the electrochemical disturbances to reach the internal layers. This was further reflected the stress recovery experiment. Concluding the increased electronic activity by the three nano-oxides over the surface of steel synergistically prevented electrochemical disturbances and microbial activities. This result increased resistance towards the degradation of the boat-building steel under corrosive environments.

\section{Conclusion}

The boat-building steel BIS 2062 surface modified with the mixtures of three multifunctional nano-oxides, $\mathrm{Fe}_{2} \mathrm{O}_{3}, \mathrm{TiO}_{2}$, and $\mathrm{CeO}_{2}$. The treatment showed uniform coating over the steel, improved the surface roughness than untreated steel, and the grain boundaries were filled with nano-oxides. The electrochemical evaluation showed that the corrosion inhibition was cathodic in nature and the optimum ratio was $0.005 \%$ each of $\mathrm{Fe}_{2} \mathrm{O}_{3}, \mathrm{TiO}_{2}$, and $0.01 \% \mathrm{CeO}_{2}$. Electrochemical impedance spectral evaluation exhibited increased polarization resistance on the surface and internal layer of the steel. The resistance to stress was improved due to the nano$3 \mathrm{MO}$ treatment over the surface. The surface modification with nano-oxides made the native $\mathrm{Fe}_{2} \mathrm{O}_{3}$ layer to behave as a semiconductor, and increased oxygen vacancies of nanooxides made increased electronic activities. This resulted in deterrence of microbial and electrochemical changes. The surface modification of boat-building steel with three multifunctional nano-oxides is having potential application in marine environments.

Acknowledgements The authors thank the Director, CIFT for encouragement to carry out the research and also thanks to the technical and supporting staffs of the Fishing Technology Division.

Funding This research did not receive any specific grant from funding agencies in the public, commercial, or not-for-profit sectors.

\section{References}

Arurault L, Monsang P, Salley J, Bes RS (2004) Electrochemical preparation of adherent ceria coatings on ferritic stainless steel. Thin Solid Films 466:75-80

Ashraf PM, Shibli SMA (2007) Reinforcing aluminium with cerium oxide: a new and effective technique to prevent corrosion in marine environment. Electrochem Commun 9:443-448

Ashraf PM, Shibli SMA (2008) Development of $\mathrm{CeO}_{2}-\mathrm{TiO}_{2}$ incorporated aluminium metal composites matrix with high resistance to corrosion and biofouling. J Solid State Electrochem 12:315-322

Barroso M, Pendlebury SR, Cowan AJ, Durrant JR (2013) Charge carrier trapping, recombination and transfer in hematite $\left(\alpha-\mathrm{Fe}_{2} \mathrm{O}_{3}\right)$ water splitting photoanodes. Chem Sci 4:2724-2734

Bethencourt M, Botana FJ, Cano MJ, Marcos M (2004) Advanced generation of green conversion coatings for aluminium alloys. Appl Surf Sci 238:278-281

Bjerklie S (2005) Thinking big with nanotechnology: nano-coatings expected to revolutionize surface finishing. Met Finish 103:46-47

Campbell CT, Peden CHF (2005) Oxygen vacancies and catalysis on ceria surfaces. Science 309:713-714

Cao M, Li Z, Wang J, Ge W, Yue T, Li R, Colvin VL, Yu WW (2012) Food related applications of magnetic iron oxide nanoparticles: enzyme immobilization, protein purification, and food analysis. Trend Food Sci Technol 27:47-55

Chandrasekar MS, Pushpavanam M (2008) Pulse and pulse reverse plating - conceptual, advantages and applications. Electrochim Acta 53:3313-3322

Chen J, Patil S, Seal S, McGinnis JF (2006) Rare earth nanoparticles prevent retinal degeneration induced by intracellular peroxides. Nat Nanotechnol 1:142-150

Chiang YM, Lavik EB, Kosacki I, Tuller HL (1996) Defect and transport properties of nanocrystalline $\mathrm{CeO}_{2-x}$. Appl Phys Lett 69:185-187

Chiang YM, Lavik EB, Kosacki I, Tuller HL (1997) Nonstoichiometry and electrical conductivity of nanocrystalline $\mathrm{CeO}_{2-x}$. J Electroceram 1:7-14

Cowan AJ, Tang JW, Leng WH, Durrant JR, Klug DR (2010) Water splitting by nanocrystalline $\mathrm{TiO}_{2}$ in a complete photoelectrochemical cell exhibits efficiencies limited by charge recombination. J Phys Chem C 114:4208-4214

Dawidczyk TJ, Walton MD, Jang WS, Grunlan JC (2008) Layer-bylayer assembly of UV-resistant poly(3,4-ethylenedioxythiophene) thin films. Langmuir 24:8314-8318

Deshpande S, Patil S, Kuchibhatla SVNT, Seal S (2005) Size dependency variation in lattice parameter and valency states in nanocrystalline cerium oxide. Appl Phys Lett 87:133113 
Dhoke SK, Khanna AS (2009) Electrochemical behavior of nano-iron oxide modified alkyd based waterborne coatings. Mater Chem Phys 117:550-556

Domínguez-Crespo MA, García-Murillo A, Torres-Huerta AM, Carrillo Romo FJ, Onofre-Bustamante E, Yanez-Zamora C (2009) Characterization of ceramic sol-gel coatings as an alternative chemical conversion treatment on commercial carbon steel. Electrochim Acta 54(10):2932-2940

Etacheri V, Valentin CD, Schneider J, Bahnemann D, Pillai SC (2015) Visible-light activation of $\mathrm{TiO}_{2}$ photocatalysts: advances in theory and experiments. J Photochem Photobiol C Photochem Rev 25:1-29

Fernando R (2004) Nanomaterial technology applications in coatings. JCT Coat Technol 1(5):32-38

$\mathrm{Fu}$ YP, Lin CH, Hsu CS (2005) Preparation of ultrafine $\mathrm{CeO}_{2}$ powders by microwave-induced combustion and precipitation. J Alloys Compds 391:110-114

Fujishima A, Honda K (1972) Electrochemical photolysis of water at a semiconductor electrode. Nature 238:37-38

Gaudon M, Pailhe N, Majimel J, Wattiaux A, Abel J, Demourgues A (2010) Influence of $\mathrm{Sn}^{4+}$ and $\mathrm{Sn}^{4+} / \mathrm{Mg}^{2+}$ doping on structural features and visible absorption properties of $\alpha-\mathrm{Fe}_{2} \mathrm{O}_{3}$ hematite. J Solid State Chem 183:2101-2109

Han Z, Zuo Y, Ju P, Tang Y, Zhao X, Tang J (2012) The preparation and characteristics of a rare earth/nano- $\mathrm{TiO}_{2}$ composite coating on aluminum alloy by brush plating. Surf Coat Technol 206:3264-3269

Hasannejad H, Shahrabi T, Jafarian M (2013) Synthesis and properties of high corrosion resistant $\mathrm{Ni}$-cerium oxide nano-composite coating. Mater Corros 64:1104-1113

Holgado JP, Alvarez R, Munuera G (2000) Study of $\mathrm{CeO}_{2}$ XPS spectra by factor analysis: reduction of $\mathrm{CeO}_{2}$. Appl Surf Sci 161:301-315

Hoshian S, Jokinen V, Hjort K, Ras RHA, Franssila S (2015) Amplified and localized photo switching of $\mathrm{TiO}_{2}$ by micro- and nanostructuring. ACS Appl Mater Interfaces 7:15593-15599

Huang JY, Lai YK, Pan F, Yang L, Wang H, Zhang KQ, Fuchs H, Chi LF (2014) Multifunctional super amphiphobic $\mathrm{TiO}_{2}$ nanostructure surfaces with facile wettability and adhesion engineering. Small $10: 4865-4873$

Husain E, Narayanan TN, Taha-Tijerina JJ, Vinod S, Vajtai R, Ajayan PM (2013) Marine corrosion protective coatings of hexagonal boron nitride thin films on stainless steel. ACS Appl Mater Interfaces 5:4129-4135

Ilevbare GO, Burstein GT (2001) The role of alloyed molybdenum in the inhibition of pitting corrosion in stainless steels. Corros Sci 43:485-513

Ishizaki T, Masuda Y, Sakamoto M (2011) Corrosion resistance and durability of superhydrophobic surface formed on magnesium alloy coated with nanostructured cerium oxide film and fluoroalkylsilane molecules in corrosive $\mathrm{NaCl}$ aqueous solution. Langmuir $27: 4780-4788$

Lamaka SV, Shchukin DG, Andreeva SDV, Zheludkevich SML, Möhwald H, Ferreira MGS (2008) Sol-gel/polyelectrolyte active corrosion protection system. Adv Funct Mater 18:3137-3147

Laurent S, Dutz S, Häfeli UO, Mahmoudi M (2011) Magnetic fluid hyperthermia: focus on superparamagnetic iron oxide nanoparticles. Adv Colloid Interface Sci 166:8-23

Lee N, Hyeon T (2012) Designed synthesis of uniformly sized iron oxide nanoparticles for efficient magnetic resonance imaging contrast agents. Chem Soc Rev 41:2575-2589

Liang J, Hu Y, Fana Y, Chen H (2013) Formation of super hydrophobic cerium oxide surfaces on aluminum substrate and its corrosion resistance properties. Surf Interface Anal 45:1211-1216

Lovern SB, Strickler JR, Klaper R (2007) Behavioral and physiological changes in Daphnia magna when exposed to nanoparticle suspensions (titaniumdioxide, nano-C60, and $\mathrm{C} 60 \mathrm{HxC} 70 \mathrm{Hx}$ ). Environ Sci Technol 41:4465-4470
Low CTJ, Wills RGA, Walsh FC (2006) Electrodeposition of composite coatings containing nanoparticles in a metal deposit. Surf Coat Technol 201:371-383

Macedo AG, Fernandes SE, Valente A, Ferreira RAS, Carlos LD, Rocha J (2010) Catalytic performance of ceria nanorods in liquid-phase oxidation of hydrocarbons with tertbutyl hydroperoxide. Molecules 15:747-765

Pailhe N, Wattiaux A, Gaudon M, Demourgues A (2008) Impact of structural features on pigment properties of $\alpha-\mathrm{Fe}_{2} \mathrm{O}_{3}$ haematite. J Solid State Chem 181:2697-2704

Sharmila R, Selvakumar N, Jeyasubramanian K (2013) Evaluation of corrosion inhibition in mildsteel using cerium oxide nanoparticles. Mater Lett 91:78-88

Sheldon BW, Shenoy VB (2011) Space charge induced surface stresses: implications in ceria and other ionic solids. Phys Rev Lett 106:216104

Tang JW, Durrant JR, Klug DR (2008) Charge carrier dynamics on mesoporous $\mathrm{WO}_{3}$ during water splitting. J Am Chem Soc 130:13885-13891

Tsunekawa S, Sahara R, Kawazoe Y, Ishikawa K (1999) Lattice relaxation of monosize $\mathrm{CeO}_{2}$ x nanocrystalline particles. Appl Surf Sci 152:53-56

Vaghari H, Sadeghian Z, Shahmiri M (2011) Investigation on synthesis, characterisation and electrochemical properties of $\mathrm{TiO}_{2}-\mathrm{Al}_{2} \mathrm{O}_{3}$ nanocomposite thin film coated on $316 \mathrm{~L}$ stainless steel. Surf Coat Technol 205:5414-5421

van de Krol R (2012) Principles of photoelectrochemical cells. In: van de Krol R, Gratzel M (eds) Photoelectrochemical hydrogen production, electronic materials: science and technology, vol 102. Springer Science + Business Media, LLC 2012. https://doi. org/10.1007/978-1-4614-1380-6_2

Voevodin N, Balbyshev VN, Khobaib M, Donley MS (2003) Nanostructures coatings approach for corrosion protection. Prog Org Coat 47:416-423

Wang R, Hashimoto K, Fujishima A, Chikuni M, Kojima E, Kitamura A, Chikuni M, Kojima E, Kitamura A, Shimohigoshi M, Watanabe T (1997) Light-induced amphiphilic surfaces. Nature 388:431-432

Woan K, Pyrgiotakis G, Sigmund W (2009) Photocatalytic carbon-nanotube- $\mathrm{TiO}_{2}$ composites. Adv Mater 21:2233-2239

Xue YJ, Liu HB, Lan MM, Li JS, Li H (2010) Effect of different electrodeposition methods on oxidation resistance of $\mathrm{Ni}-\mathrm{CeO}_{2}$ nanocomposite coating. Surf Coat Technol 204:3539-3545

Yang L, Cao Z, Sajja HK, Mao H, Wang L, Geng H, Xu H, Jiang T, Wood WC, Nie S, Wang YA (2008) Development of receptor targeted magnetic iron oxide nanoparticles for efficient drug delivery and tumor imaging. J Biomed Nanotechnol 4:439-449

Yeh J-M, Weng C-J, Liao W-J, Mau Y-W (2006) Anti-corrosively enhanced $\mathrm{PMMA}-\mathrm{SiO}_{2}$ hybrid coatings prepared from the sol-gel approach with MSMA as the coupling agent. Surf Coat Technol 201:1788-1795

Zhang CJ, Michaelides A, King DA, Jenkins SJ (2009) Oxygen vacancy clusters on ceria: decisive role of cerium $f$ electrons. Phys Rev B Condens Matter Mater Phys 79:075433

Zhang Q, Rao G, Rogers J, Zhao C, Liu L, Li Y (2015) Novel antifouling $\mathrm{Fe}_{2} \mathrm{O}_{3} / \mathrm{TiO}_{2}$ nanowire membranes for humic acid removal from water. Chem Eng J 271:180-187

Zheng Q, Zhou B, Bai J, Li L, Jin Z, Zhang J, Liu Y, Cai W, Zhu X (2008) Self organized $\mathrm{TiO}_{2}$ nanotube array sensor for the determination of chemical oxygen demand. Adv Mater 20:1044-1049

Publisher's Note Springer Nature remains neutral with regard to jurisdictional claims in published maps and institutional affiliations. 